\title{
Medical Legal Forum: Simplified, Real-time, Free access to the Complete Medical Record in the NICU is Coming with Implementation of the 21st Century Cures Act
}

Jonathan Fanaroff, MD, JD, Rolbert Turbow, MD, JD

Gilbert Martin, MD

Parents of NICU patients have had the right to review their child's medical records for many years, but in the past such efforts required trips to the medical records department in the sub-basement, long delays, and the significant costs of copying the records. In recent years with the shift to electronic medical records and the development of patient portals, families have had an easier time accessing some, but not all, medical records. This is about to change with the implementation of a rule from the Federal Office of the National Coordinator for Health IT requiring health systems to provide greater access to patient health records.

\section{"This is about to change with the implementation of a rule from the Federal Office of the National Coordinator for Health IT requiring health systems to provide greater access to patient health records."}

The rule is part of the implementation of the $21^{\text {st }}$ Century Cures Act passed by Congress in 2016. The "Cures Act" was originally designed to accelerate medical product development and to bring new innovations to patients who need these products faster. The program also allowed patients to access all the health information in their electronic medical records without charge by their healthcare provider. The original deadline for the rule, November 2, 2020, was moved to April 5, 2021, due to the coronavirus pandemic. Patients will have access to the following types of clinical notes:

$\begin{array}{ll}\text { - } & \text { Consultation notes } \\ \text { - } & \text { Discharge summary notes } \\ \text { - } \quad \text { Imaging narratives } \\ \text { - } \quad \text { Laboratory report narratives } \\ \text { - } \quad \text { Procedore notes } \\ \text { - Progress notes }\end{array}$

There are limited exceptions. These include certain psychotherapy notes by mental health professionals as well as information gathered for use in civil or criminal proceedings. A note can also be protected if it places the patient in potential danger, such as

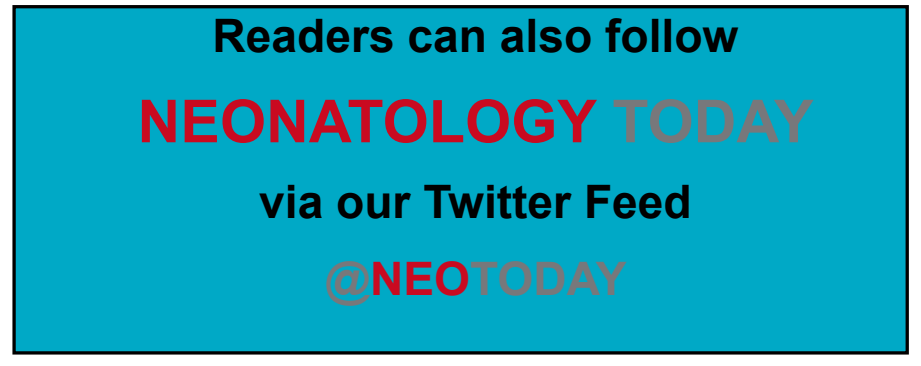

a discussion about domestic violence when the abuser can access the information. Additionally, certain health information for adolescents may be protected from access by the parents. It will be important to work with hospital legal and compliance experts to determine the specific application of the rule at your institution.

An important second aspect of the rule is penalties for anti-competitive behavior and information blocking that impedes the exchange of medical information. For example, some health IT vendors had a "gag clause" prohibiting the sharing of screenshots. These non-disclosure clauses hinder efforts to improve safety and openly discuss safety concerns.

The destruction of 'data silos' and mandated interoperability is designed to improve care and decrease costs by allowing patients to control their electronic health information, download the information to their smartphones, and examine the data with the apps of their choice. For years there has been an issue of who 'owns' patient health data, and this question has clearly been answered in favor of patients.

\section{"An important second aspect of the rule is penalties for anti-competitive behavior and information blocking that impedes the exchange of medical information. For example, some health IT vendors had a "gag clause" prohibiting the sharing of screenshots. These non-disclosure clauses hinder efforts to improve safety and openly discuss safety concerns."}

What impact will free, easy access to the medical record have in the NICU? Certainly, some additional education may be necessary. For example, many laboratory 'normal' values reflect data for adults, not neonates. Additionally, very sensitive maternal information, such as herpes status and pregnancy history, is part of the neonatal medical record as well. Ultimately the change will likely be very positive, as with most improvements in transparency. Indeed, while a busy NICU team is caring for multiple patients, a family is focused on just one patient and may catch and prevent errors of omission.

Let us not forget that in 2013, the NICU Parent Network created the "NICU Parent's Bill of Rights." These ten statements are listed from the perspective of the NICU baby. An example of one statement is, "my parents are my voice and my best advocates; therefore, hospital policies, including visiting hours and rounding, should be as inclusive as possible.

The Cures Act "Final Rule," which was issued on October 29, 2020 , provides our healthcare system additional flexibility and clarifies privacy protections. Healthcare workers face quite a challenge. They must try to take the safest possible care of patients while working in extraordinarily complex systems. The 
High-Reliability theory offers insight into this dilemma. Increasing reliability has the potential to not only improve outcomes but also to decrease a hospital's liability.

The authors have no conflicts of interests to disclose.

NT

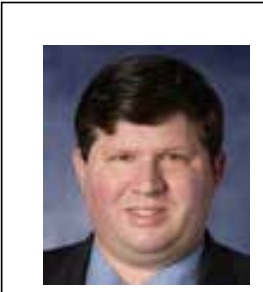

Corresponding Author

Jonathan Fanaroff,, MD, JD, FAAP

Professor of Pediatrics

Case Western Reserve University School of Medicine

Director, Rainbow Center for Pediatric Ethics

Rainbow Babies \& Children's Hospital

Cleveland, Ohio

Email: Jonathan Fanaroff <imf20@case.edu>

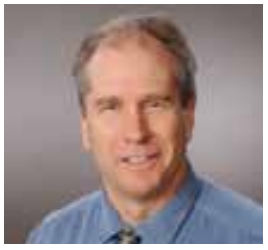

Bob Turbow, M.D., J.D.

Neonatologist and Chief Patient Safety Officer

Dignity Health of the Central Coast

(805)739-3246

Email: bob.turbow@dignityhealth.org

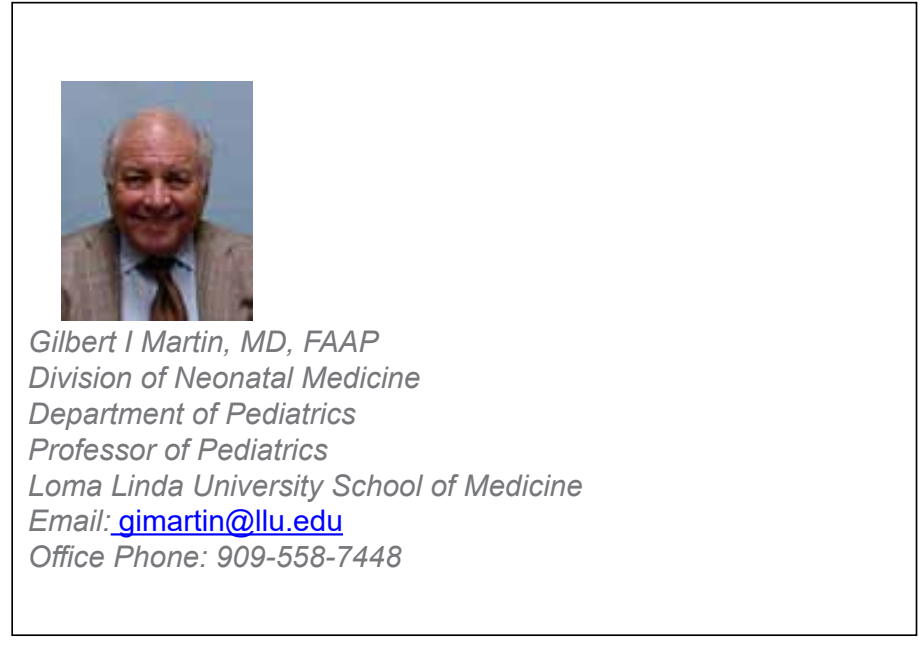

Disclaimer:

This column does not give specific legal advice, but rather is intended to provide general information on medicolegal issues. As always, it is important to recognize that laws vary state-to-state and legal decisions are dependent on the particular facts at hand. It is important to consult a qualified attorney for legal issues affecting your practice.

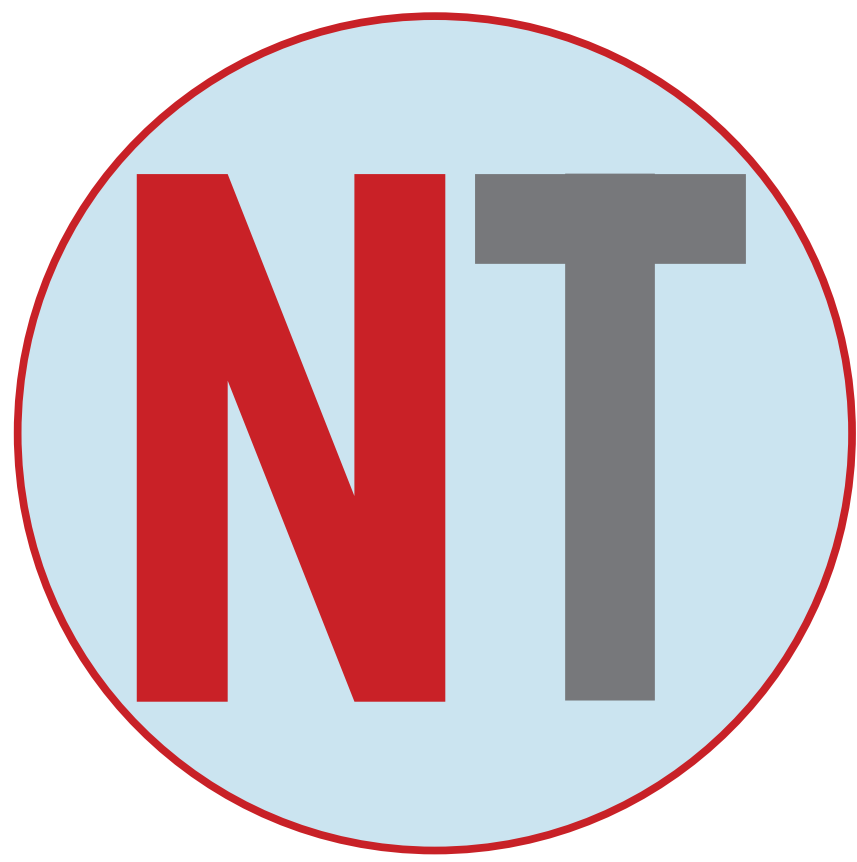

NEONATOLOGY TODAY is interested in publishing manuscripts from Neonatologists, Fellows, NNPs and those involved in caring for neonates on case studies, research results, hospital news, meeting announcements, and other pertinent topics.

Please submit your manuscript to: LomaLindaPublishingCompany@gmail.com 